\title{
Development of damage assessment package for building with isolation system and its application to 2011 Tohoku earthquake
}

\section{Akira Mita, Ken Ichimura}

Akira Mita, Ken Ichimura, "Development of damage assessment package for building with isolation system and its application to 2011 Tohoku earthquake," Proc. SPIE 8345, Sensors and Smart Structures Technologies for Civil, Mechanical, and Aerospace Systems 2012, 834539 (6 April 2012); doi: 10.1117/12.915578 Health Monitoring, 2012, San Diego, California, United States 


\title{
Development of damage assessment package for building with isolation system and its application to 2011 Tohoku Earthquake
}

\author{
Akira Mita* ${ }^{*}$ Ken Ichimura \\ Department of System Design Engineering, Keio University, 3-14-1 Hiyoshi, Kohoku-ku, \\ Yokohama 223-8522, Japan
}

\begin{abstract}
We developed a damage assessment package to assess buildings with various isolation systems. The package provides seven items to be used for damage assessment based on ARX method, MOESP method and double integration of acceleration data. The necessary condition for the package is to have a monitoring system with accelerometers at least at three levels i.e. on foundation, isolation layer and on top floor or roof of the building. Using this package, the performance of the isolation systems as well as superstructure during the earthquake can be quantitatively estimated. The package was tested for a 7-story base-isolated building in Yokohama, Japan. The building experienced the 2011 Tohoku Earthquake of the moment magnitude 9.0.
\end{abstract}

Keywords: Isolation, ARX, MOESP, Subspace identification, Structural health monitoring, Damage assessment, Tohoku Earthquake

\section{INTRODUCTION}

The Tohoku Earthquake hit northern Japan on March 11 in 2011. The moment magnitude of the earthquake was 9.0. Due to this large energy release, many buildings especially with long natural periods including isolated buildings had been shaken for long duration up to say 10 minutes over Japan. Many base-isolated buildings experienced this earthquake and fortunately no major damage was reported even for those in the near-field. Such long duration of the shaking had not been considered when those buildings were designed as the code did not require. Thus, the quantitative evaluation of the isolated buildings was demanded using recorded data during the 2011 Tohoku Earthquake. For this purpose, we propose a comprehensive damage assessment package for buildings with isolation system. In this paper, this assessment package is briefly explained.

\section{DAMAGE ASSESSMENT PACKAGE FOR BUILDING WITH ISOLATION SYSTEM}

The list of items to be evaluated is provided in Table 1. These items were selected to check if the performance of the whole building system as well as isolators was satisfactory or not. In addition, we would like to know the remaining capacity of the isolators, especially damping devices, as they absorbed a lot of energy. The energy absorbed by these devices can be estimated from items 4 and 5 .

The most monitoring systems consist of accelerometers only. Typical sensor location is illustrated in Figure 1 . The sensors are typically installed on foundation, on top of isolation layer and top floor. Installation of displacement sensor is very rare. For items 1 and 2, the major task for us is to decide the time frame to be used for running ARX method and appropriate number of model order. For item 3, we have to determine the appropriate size of Hankel matrix to be used MOESP ${ }^{[1]}$ method. For last items 4, 5, 6 and 7, we have to decide the cut-off frequency for the high-pass filter and its order. Discussion of these aspects will be presented in the following chapter with examples applied to the real data.

*mita@sd.keio.ac.jp; phone \& fax +81 45 566-1776

Sensors and Smart Structures Technologies for Civil, Mechanical, and Aerospace Systems 2012,

edited by Masayoshi Tomizuka, Chung-Bang Yun, Jerome P. Lynch, Proc. of SPIE Vol. 8345,

$834539 \cdot$ - (c) 2012 SPIE · CCC code: 0277-786X/12/\$18 - doi: 10.1117/12.915578

Proc. of SPIE Vol. 8345 834539-1 
Table 1. Items for damage assessment of building with isolation system

\begin{tabular}{|c|l|l|}
\hline No. & \multicolumn{1}{|c|}{ Item } & \multicolumn{1}{|c|}{ Tool } \\
\hline 1 & $\begin{array}{l}\text { Time-dependent natural frequencies and damping ratios of the } \\
\text { whole structure using }\end{array}$ & Running ARX method \\
\hline 2 & $\begin{array}{l}\text { Time-dependent natural frequencies and damping ratios of the } \\
\text { superstructure }\end{array}$ & Running ARX method \\
\hline 3 & Complex mode shapes considering multiple outputs & $\begin{array}{l}\text { MOESP method (subspace } \\
\text { identification method) }\end{array}$ \\
\hline 4 & Restoring force history of the isolator & $\begin{array}{l}\text { Double integration of acceleration } \\
\text { data with high-pass filter }\end{array}$ \\
\hline 5 & Trajectory of the isolator & $\begin{array}{l}\text { Double integration of acceleration } \\
\text { data with high-pass filter }\end{array}$ \\
\hline 6 & Story drift of the superstructure & $\begin{array}{l}\text { Double integration of acceleration } \\
\text { data with high-pass filter }\end{array}$ \\
\hline 7 & Accumulative displacement of isolator & $\begin{array}{l}\text { Double integration of acceleration } \\
\text { data with high-pass filter }\end{array}$ \\
\hline
\end{tabular}

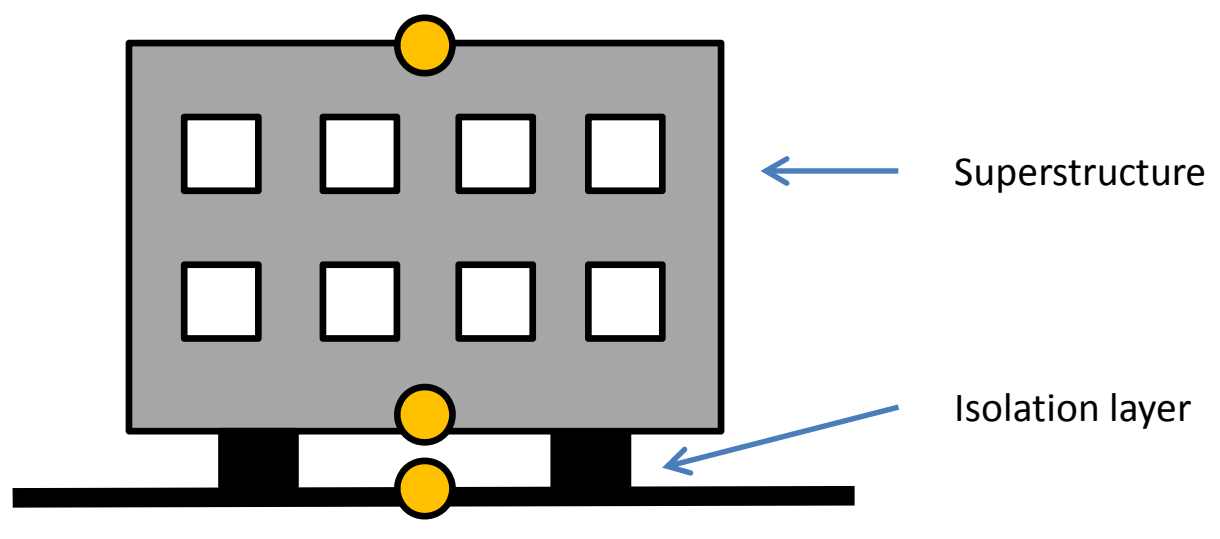

Figure 1. Base-isolated building and sensor locations

\section{APPLICATION OF THE PACKAGE TO 7-STORY BASE-ISOLATED BUILDING}

The damage assessment package is tested for a 7-story base-isolated building located on Hiyoshi Campus of Keio University. The building is equipped with web-based monitoring system consisting of accelerometers and displacement meters. We will apply the package only using acceleration data obtained by this monitoring system on March 11, 2011 for the Tohoku Earthquake. Typical acceleration time histories recorded in the building are shown in Figure 3 and 4 . The rectangular boxes represent the time frames corresponding to primary phase, principal phase and coda phase, respectively. 


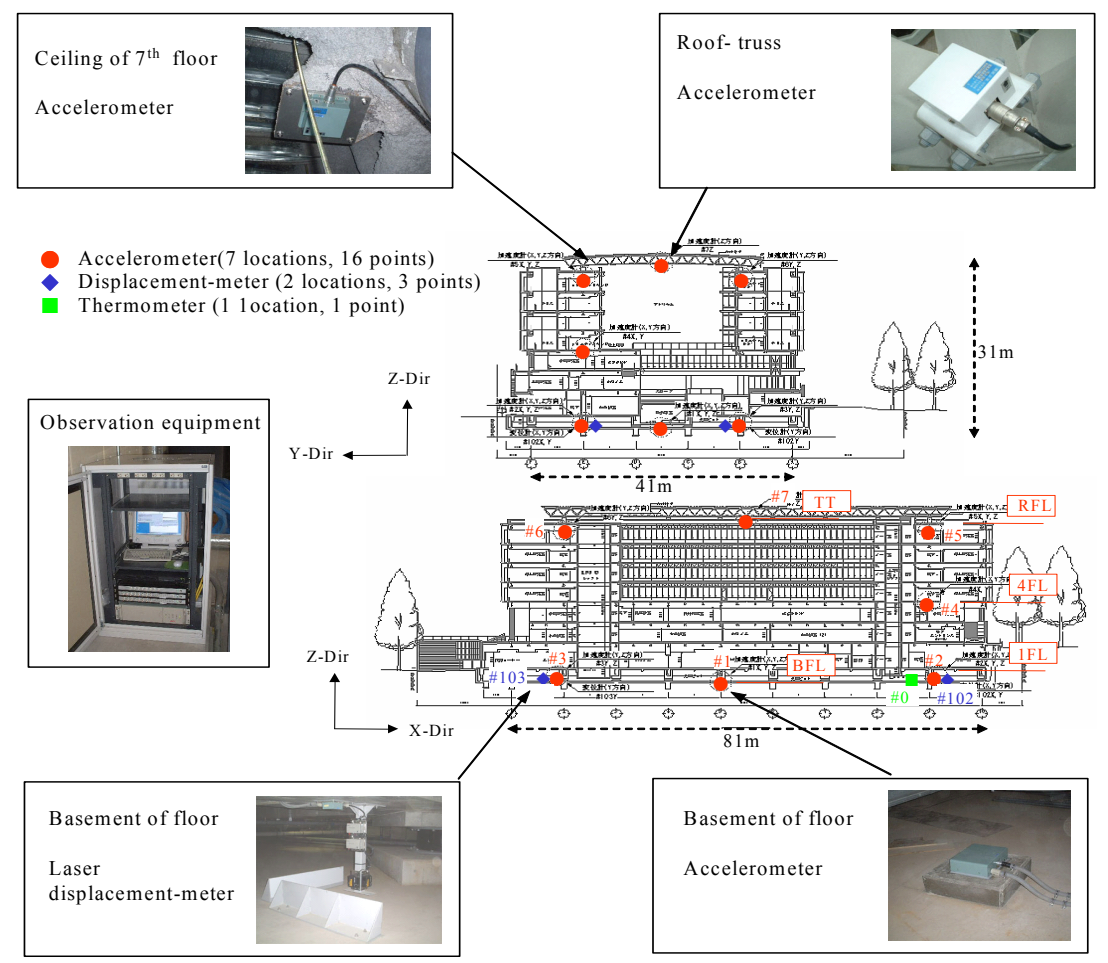

Figure 2. 7-story base-isolated building on Hiyoshi Campus of Keio University and monitoring system
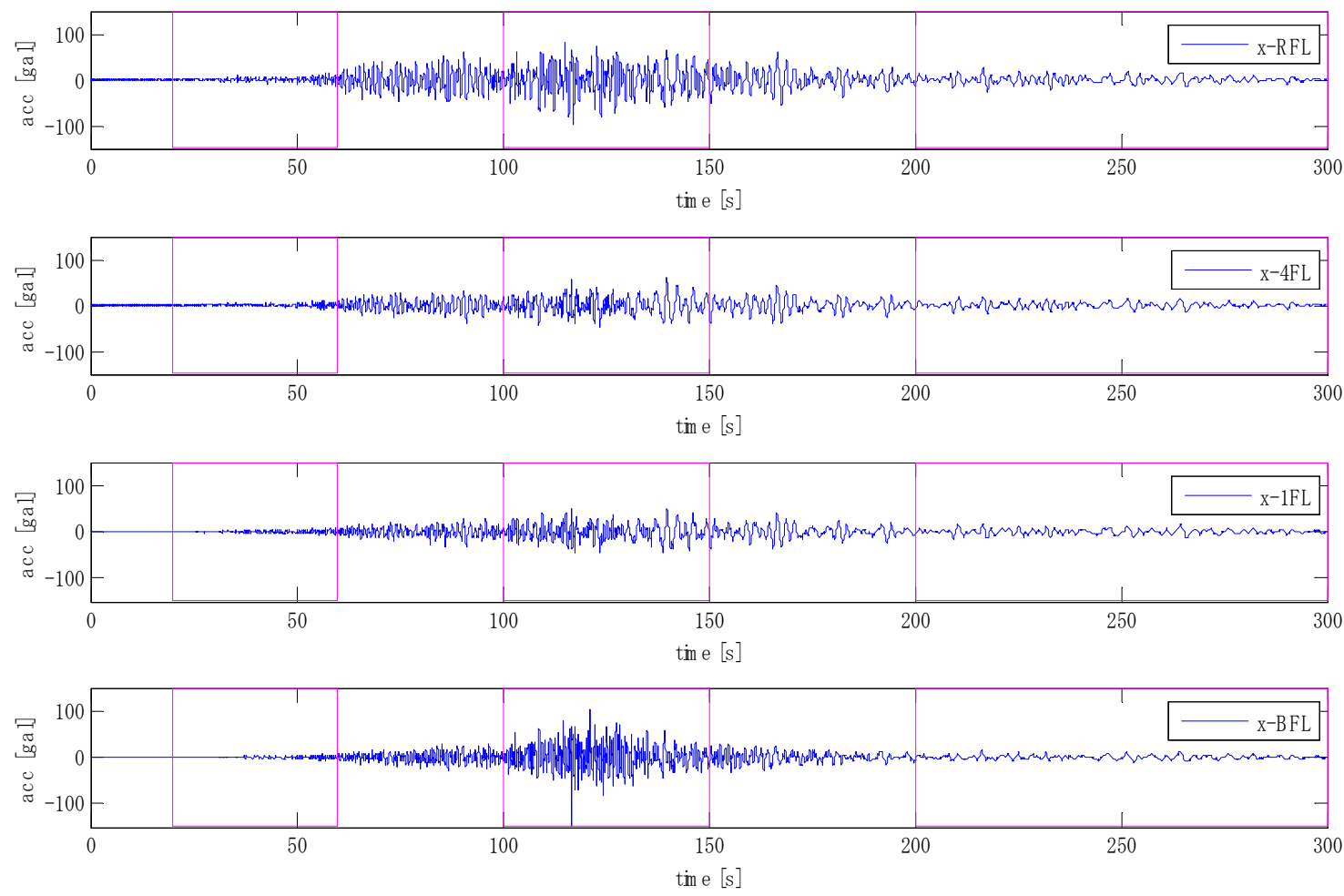

Figure 3. Acceleration time histories recorded at BFL, 1FL, 4FL and RFL in $\mathrm{x}$ direction. 

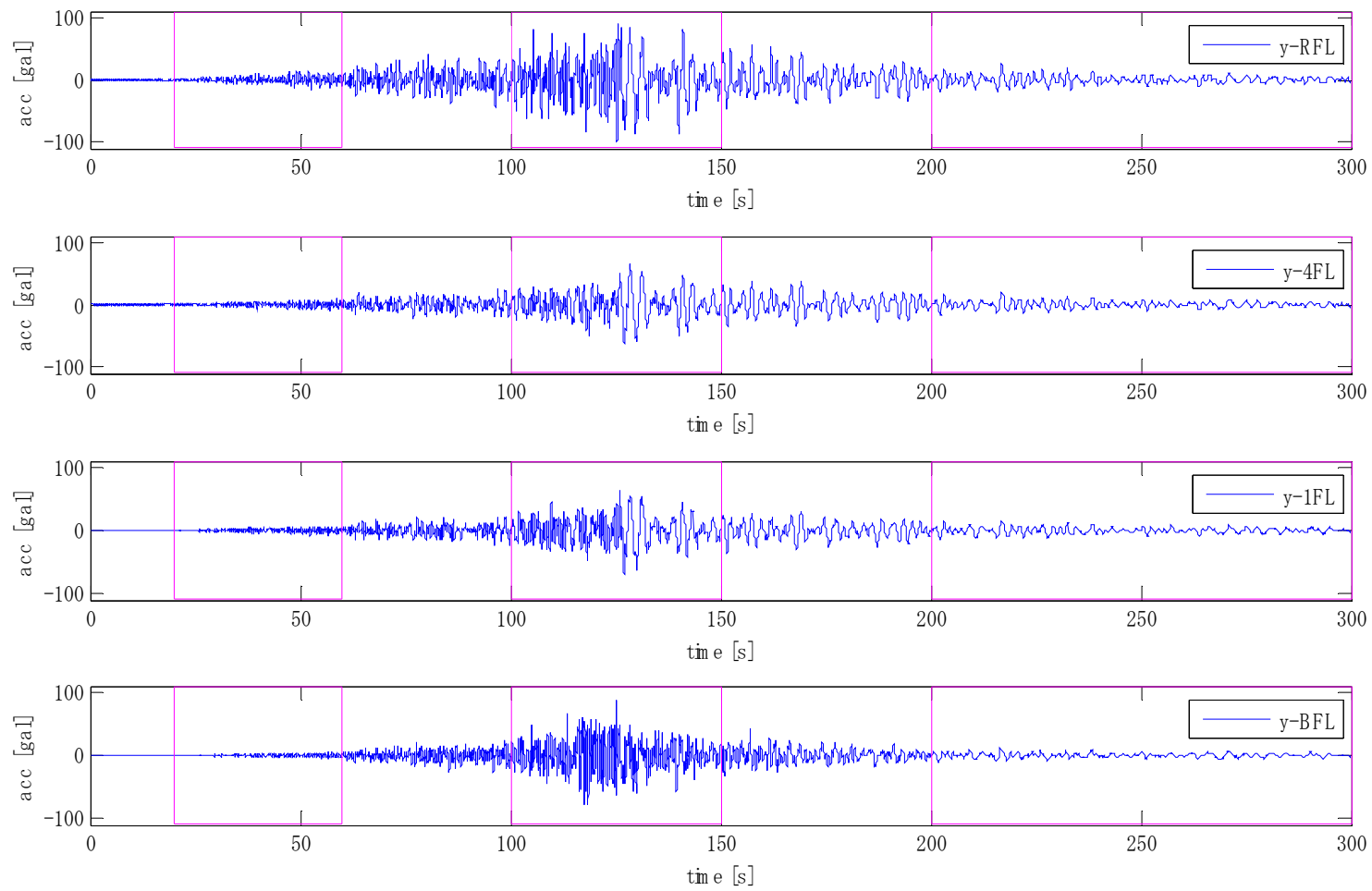

Figure 4. Acceleration time histories recorded at BFL, 1FL, 4FL and RFL in y direction.

\subsection{Natural frequencies and damping ratios based on running ARX method}

The schematics of ARX model is presented in Figure 5. The ARX parameters for the base-isolated building were determined considering Akaike Information Criteria. As we normally need only first two modes for the isolated building, the order for AR is typically chosen to be 10 thorough 15 . The number of corresponding X parameters was around 5 . The natural frequencies and damping ratios of first and second modes were automatically determined using several rules such as poles with proper damping ratios, small area of confidence area and existence of conjugate pairs. The first natural frequencies and damping ratios for the whole structure are plotted in Figure 6. Those for the superstructure are plotted in Figure 7. The window length for the running ARX method is $10 \mathrm{~s}$. The time histories were used after resampling the original digitized data with $20 \mathrm{~Hz}$. The original sampling frequency of the monitoring system is $100 \mathrm{~Hz}$. In addition, a band pass filter between 0.1 and $4.0 \mathrm{~Hz}$ was applied using $3^{\text {rd }}$ order Butterworth filter. From the figures, we can observe the change of modal properties during the earthquake very clearly. During the principal phase, the first natural frequency of the whole structure was around $0.5 \mathrm{~Hz}$ that was close to the design frequency. The damping ratio achieved during this period was more than $20 \%$. Thus the isolating system performed very well. Meanwhile the first natural frequency of the superstructure was kept around $1.0 \mathrm{~Hz}$. This fact implies that the superstructure was within elastic range.

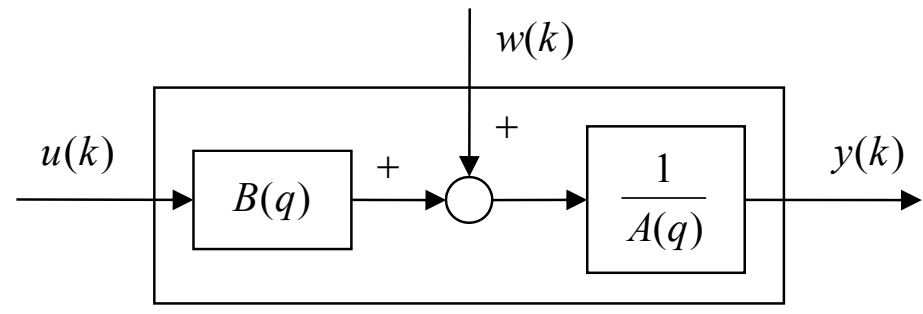

Figure 5. ARX model 

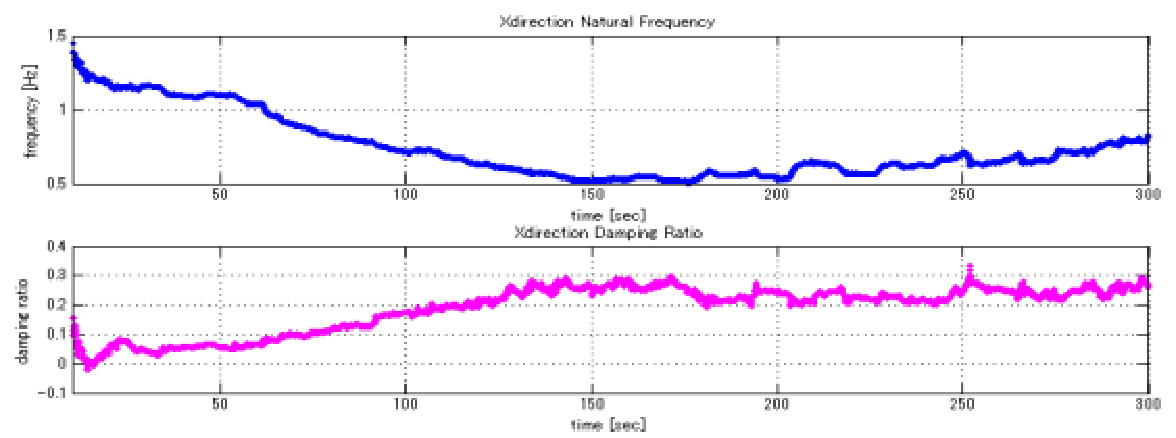

Figure 6. Natural frequencies and damping ratios for the first mode of whole structure in $\mathrm{x}$ direction.
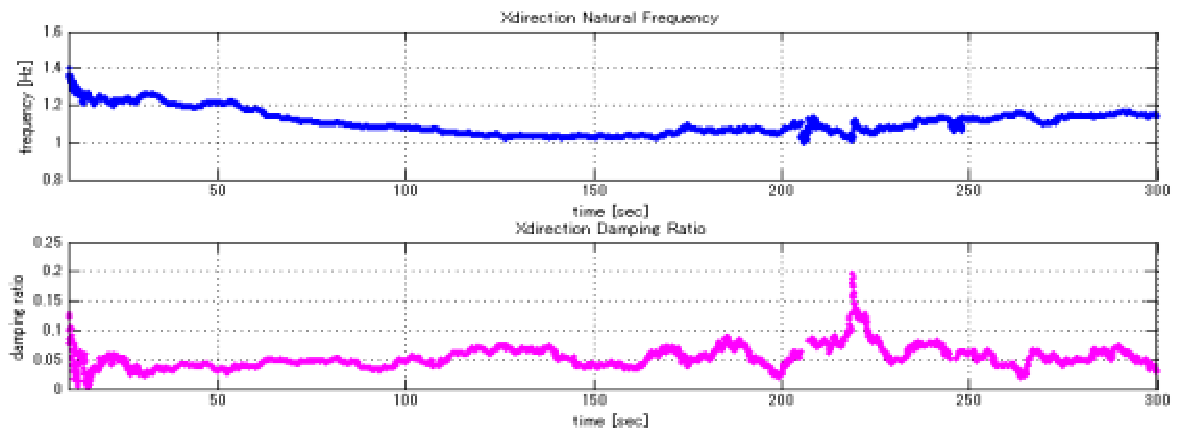

Figure 7. Natural frequencies and damping ratios for the first mode of the superstructure in $\mathrm{x}$ direction.

\subsection{Complex mode shapes based on MOESP method}

One of subspace identification methods, MOESP, was chosen to obtain complex mode shapes as it can deal with multiinput and multi-output. The size of Hankel matrix is the key issue to control the performance of the method. We conducted extensive evaluation of the size and found that the effects of the size were not significant if the proper range of the Hankel matrix is used. In Figure 8, complex mode shapes corresponding to pre-main shock, main shock and postmain shock are plotted. The amplitude of the mode shapes was normalized to be unit amplitude at the top of the building. The imaginary parts of the mode shapes indicate the phase shift for the mode. We see relatively large imaginary part for the principal phase and coda phase. This is due to the large damping force provided by damping devices installed in the isolation layer.
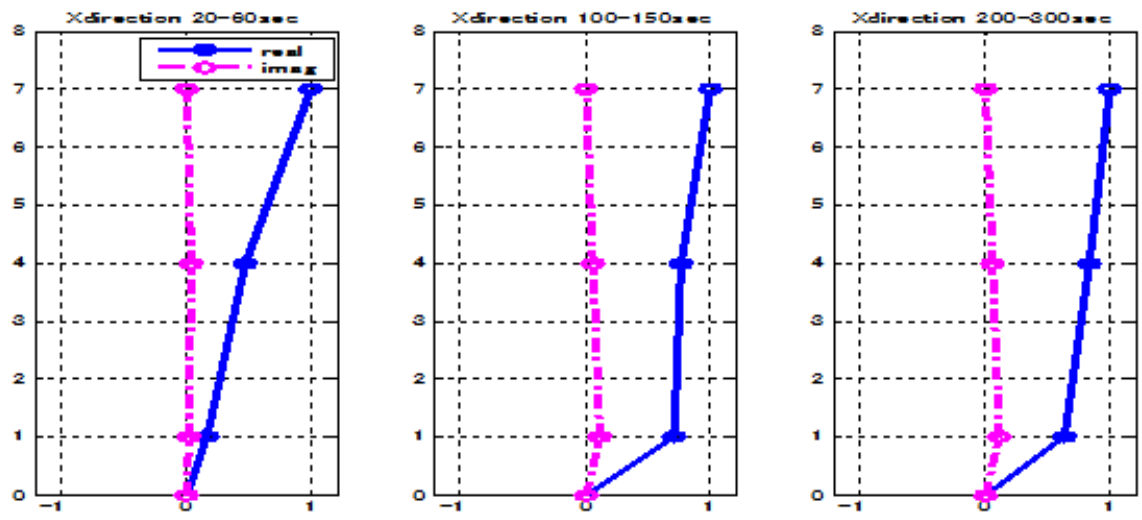

Figure 8. Complex mode shapes in $\mathrm{x}$ direction for primary phase, principal phase and coda phase. 


\subsection{Double integration of acceleration data}

Items 4, 5, 6 and 7 require the displacement time histories. However, we usually do not install displacement sensor into buildings as the displacement sensor for measuring large stroke is expensive and installation work is not easy. Thus we have to rely on accurate acceleration data. The acceleration data in this monitoring system was recorded using servoaccelerometers with good accuracy. In addition we only need relative displacement so that relatively good accuracy for displacement obtained from double integration of acceleration was expected. However, to remove harmful noise, we need to apply high-pass filter. Wiener-Khinchin theorem indicates that the loss of the power in frequency domain results in loss of amplitude in the time domain. From this observation, we determined the filter. In Figure 9, restoring forces are plotted for several time partitions using the high-pass filter of cut-off frequency $0.1 \mathrm{~Hz}$.
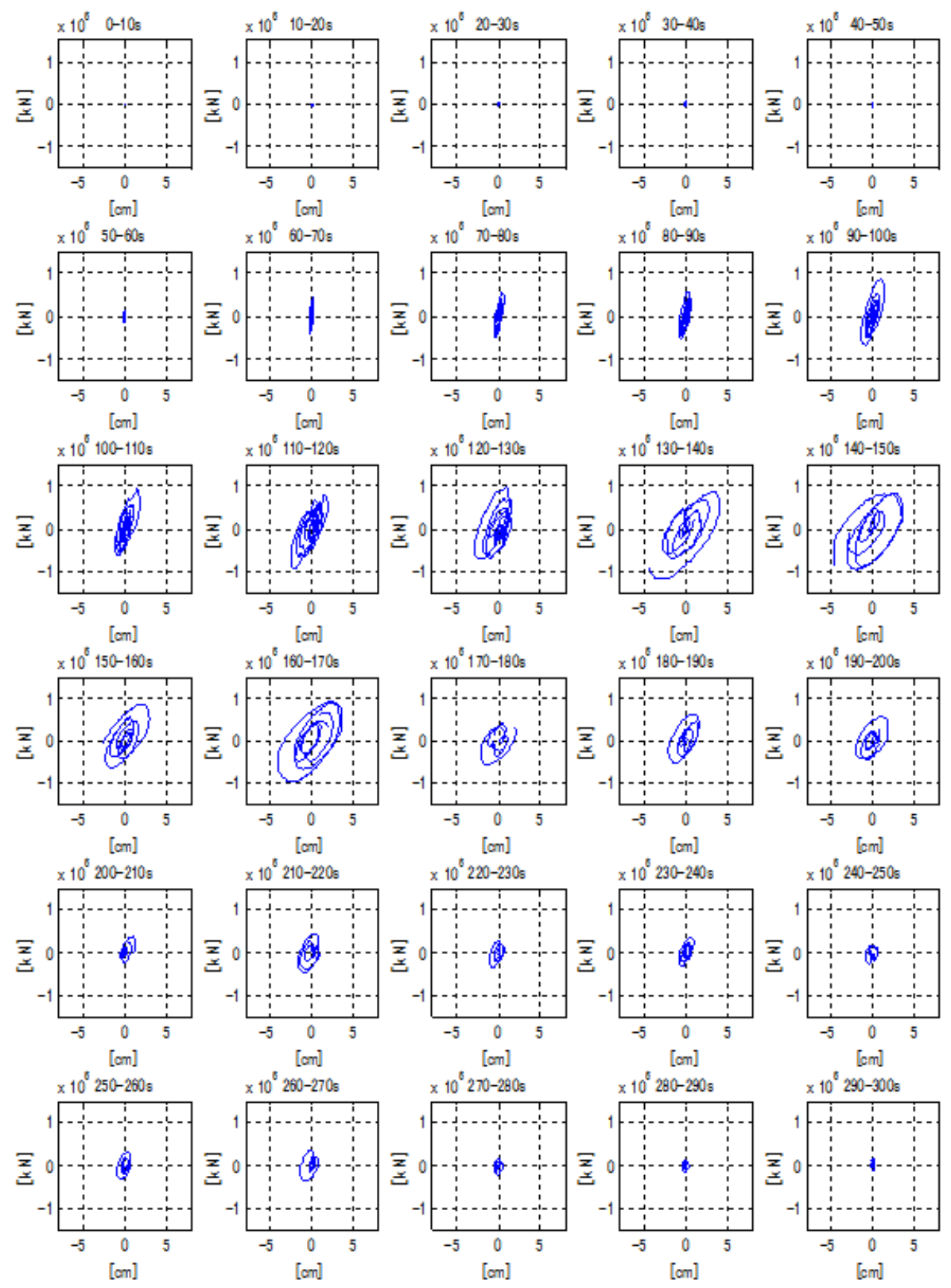

Figure 9. Restoring force of the isolation layer in $\mathrm{x}$ direction using $0.1 \mathrm{~Hz}$ cut-off frequency for high-pass filter 
The trajectory of the isolation layer is depicted in Figure 10. It is observed that the largest displacement was slightly more than $6 \mathrm{~cm}$. Using the same procedure, we calculated the largest story drift for the superstructure. The estimated largest value was less than $0.1 \%$ so that the superstructure was within elastic range. Finally, the accumulated displacement of the isolation layer was obtained. For 2011 Tohoku Earthquake, the accumulated displacement motion of the isolation layer of this building reached about $7 \mathrm{~m}$. This value was much larger for the isolated buildings in the nearfield.

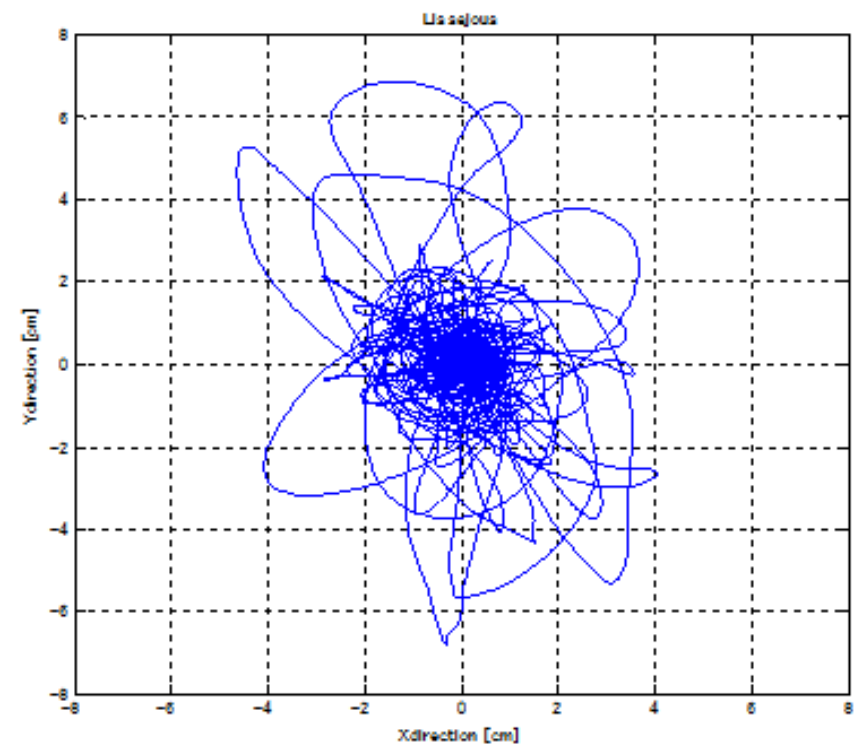

Figure 10. Trajectory of the isolation layer for 2011 Tohoku Earthquake.

\section{CONCLUDING REMARKS}

We developed a damage assessment package to assess buildings with various isolation systems. Seven items to be used for damage assessment are based on running ARX method, MOESP method and double integration of acceleration data with appropriate filtering. The package uses the acceleration data only as accelerometer is the most popular and easy-toinstall sensor. The accelerometers are required to be installed at least at three locations i.e. on foundation, on isolation layer and on top floor or roof of the building. The performance of the isolation and building systems as well as damage caused by the earthquake can be quantitatively estimated. The package was applied to a 7-story base-isolated building in Yokohama where the building experienced the 2011 Tohoku Earthquake of the magnitude 9.0. The results showed good feasibility of the proposed assessment package.

\section{ACKNOWLEDGEMENT}

This work was supported in part by the Grant-in-Aid No. 22310103 (PI: A. Mita) and the Grant-in-Aid for the Global Center of Excellence Program for the "Center for Education and Research of Symbiotic, Safe and Secure System Design" from the Ministry of Education, Culture, Sport, Science and Technology in Japan.

\section{REFERENCES}

[1] Verhaegen M, Dewilde P. "Subspace model identification part 1. The output-error state-space model identification class of algorithms," International Journal of Control 1992; 56(5):1187-1210. 